\title{
CORRESPONDENCE
}

\section{Animal pain}

SIR - Your editorial on "Protection for laboratory animals" (Nature 17 September, p.173) is most welcome. It is no longer enough for universities and research workers to maintain an aloof silence or to claim that they are working within the law. Public opinion will not accept such an attitude. I am sure that there are many scientists who regard themselves as animal lovers, or even just humane people, but believe sincerely in the benefits that animal experiments have brought to mankind and to animals themselves. Perhaps we should begin to speak out and not accept false propaganda on the one hand or the sanctity of all knowledge on the other.

A first step would be to show that scientists do care about animals and do think deeply about what they propose to do, the best way of doing it and just why they are doing it. Your proposal to set up committees at many centres is timely. Indeed, committees of this sort have already been formed at several universities and are under discussion elsewhere. If such bodies were made responsible for approving applications for licences and if necessary interviewing applicants, this alone would help to ensure that the work is not unnecessarily repetitious, that an excessive number of animals is not used and that alternatives have been considered. Such advice would be particularly helpful to inexperienced workers who often receive only very limited and specialized training.

Is it not time that all new licence holders were asked to attend a short formal course on animal welfare, breeding, feeding, preoperative and postoperative care, anaesthesia, use of drugs etc.? After all, if public money can be spent on sending general practitioners to courses on intrauterine memory, would the public not agree that funds should be available for training biologists in the basic practical care of those who are used to benefit mankind but are given no choice in the matter?

Department of Human Biology and Anatomy, University of Sheffield, UK

SIR - Your leading article "Protection for laboratory animals?"' (Nature 17 September, p.173) mentions " widespread incoherence", and may I respectfully suggest that a number of misleading statements have hardly clarified the situation. For instance you say, "Thus the 1876 Act requires that experiments involving pain must be carried out under anaesthesia (and the Home Secretary has not waived this regulation for the past half-century)". Yet, according to Home Office Statistics of experiments on living animals (Great Britain, 1980), 3,730,588 experiments, "calculated to inflict pain", were carried out without any anaesthetic (certificate A); 677,607 experiments were carried out in which the animals were allowed to recover from the anaesthetic (certificate B), and only 171,283 experiments ( 3.7 per cent of the total) were carried out with anaethesia for the whole experiment.

Many of the procedures carried out under certificate A must, by their very nature, cause great distress. For example in 1980, 484,849 animals were used in acute toxicity tests, of which the $\mathrm{LD}_{50}$ is an example. In this case a recent government committee ${ }^{1}$ conceded, " . . . $\mathrm{LD}_{50} \mathrm{~s}$ must cause appreciable pain to a proportion of the animals subjected to them". Most experiments involving application of substances to animals' eyes, and psychological experiments employing aversive stimuli, are two more examples of procedures carried out under certificate $\mathrm{A}$.

The Council of Europe's discussion of article 8 of the draft convention is not concerned with permitting "licensed experiments causing pain without anaesthesia". Rather it is debating the presence of a pain clause which seeks to regulate the severity and duration of pain inflicted during the course of the experiment.

In Britain the pain condition directs that animals suffering pain which is "severe" or "likely to endure" should be painlessly killed "if the main result of the experiment has been achieved". Or if they are suffering "severe pain which is likely to endure", they should be painlessly killed.

Unfortunately no one has ever defined "severe" or "likely to endure". Indeed it is impossible to define "severe" since any assessment is largely subjective. (The $\mathrm{LD}_{50}$ test is allowed to proceed for 14 days, unless death intervenes, but does this contravene the pain condition?) Here lies the central point - pain cannot be regulated. Realistically legislation can only license researchers, register premises and prohibit certain procedures. For example, in Great Britain licensees are not allowed to use animals to acquire manual dexterity.

The legislative way forward is therefore to prohibit those procedures which have become unacceptable in an evolving moral climate.

ROBERT SHARPE

Sheffield, UK

Report on the LD50 Test, Advisory Committee on the Administration of the Cruelty to Animals Act 1876 ( $\mathrm{Hom}$ Office, 1.ondon 1979).

\section{Anti-social?}

SIR - In his address to the British

Association ${ }^{1}$, Sir Edmund Leach states that he encounters biologists who refer to "primitive" and "advanced" populations, and he goes on to say that these unfortunate individuals inevitably associate the advanced category with the group to which they belong. Later in his address Professor Leach refers to physical anthropology as a "tiny, rather off-beat subbranch of the general field of anthropology" and that the "variety of human culture" (social anthropology) is "the main concern of anthropologists"'. Perhaps I am being "astonishingly naive" (an apparent failing of those interested in the trivia of human origins) if I ask whether it was merely coincidence that social anthropology is "the particular human collectivity to which the author himself happens to belong"?

Professor Leach proposes that Wilberforce was essentially correct in seeing an unbridgeable gap between man and ape. The basis for this assertion is the supposed uniqueness of human language. However, the fact that Leach, a social anthropologist, should use such an important occasion as the 150th BA anniversary to put forward a model of the relationship of man to the primates testifies to physical anthropology being more than off-beat, and to the continuing primacy of Darwinian ways of thought. Is it likely that speculations based on miscellaneous observations of the variety of human culture will be able to solve the problem of how, why and when the divide between humans and apes occurred, let alone define the nature of it? Palaeoanthropology and various branches of biology are in the best position to test such a proposition, especially given that the foundation of human language is ultimately anatomical.

In the early 1970s Professor Leach launched an attack on the archaeologists ${ }^{2}$ largely on the grounds that they were poor social anthropologists. Now it is the turn of the biological anthropologists, although this time the crime is that of not being social anthropologists at all.

ROBERT FOIEY

Department of Anthropology, University of Durham, Durham, UK

I. Leach, E.R. Nature 293, 19-21 (1981).

2. Leach, E.R. in The Explanation of Culture Change (ed Refrew, C.) (Duckworth, L ondon, 1973).

\section{Incendiary subject}

SIR - Perhaps you are right, after all, to describe Dr Rupert Sheldrake's $A$ New Science of Life as a book for burning (Nature 24 September, p.245). For after seeing the disastrous effect Sheldrake's book has wrought upon the detachment, not to say the common sense, of one with the responsibilities of the editorship of Nature, I shudder to contemplate the effect upon the ordinary man.

But perhaps it is the influence of a pulpit from which to denounce scientific heresies that is the danger, rather than the book itself. For surely there is nothing in the book to raise excitement to the point of lumping together "creationists, anti-reductionists, neoLamarckians and the rest". For scientists, the worst a book can do is to waste their time. You could have served us better by arranging for the publication of two careful and opposed critical reviews. For non-scientists, unhelpful books abound. Their ability to mystify science is as nothing compared with strenuous attempts to declare an orthodoxy.

Robert Hedies

Oxford University, UK

Si $\mathrm{R}$ - Before reading "A book for burning" in which Sheldrake's work $A$ New Science of Life is criticized (Nature 24 September, p.245), I did not think I would have to ask a Nature leader writer to read or re-read Milton's A reopagitica - "as good almost kill a man as kill a good book. Who kills a man kills a reasonable creature, God's image; but he who destroys a good book, kills reason itself, kills the image of God, as it were in the eye. Many a man lives a burden to the earth; but a good book is the precious life-blood of a master spirit, embalmed and treasured up on purpose to a life beyond life".

Continued on page 594 


\section{CORRESPONDENCE}

\section{Continued from page 506}

In case some legalistic quibble is to be put on the world "good", Milton clears the point in a famous passage.

"Good and evil we know in the field of this world grow up together almost inseparably; and the knowledge of good is so involved and interwoven with the knowledge of evil, and in so many cunning resemblances hardly to be discerned, that those confused seeds which were imposed upon Psyche as an incessant labour to cull out, and sort asunder, were not more intermixed. It was from out the rind of one apple tasted, that the knowledge of good and evil, as two twins cleaving together, leaped forth into the world. And perhaps this is that doom which Adam fell into of knowing good and evil, that is to say of knowing good by evil. As therefore the state of man now is; what wisdom can there be to choose, what continence to forbear without the knowledge of evil? $\mathrm{He}$ that can apprehend and consider vice with all her baits and seeming pleasures, and yet abstain, and yet distinguish, and yet prefer that which is truly better, he is the true wayfaring Christian."

F.W. Cousins

London SWI, UK

SIR - I must voice my grave concern that, in the influential editorial pages of Nature, reasoned argument has given way to the emotional outburst of your comment "A book for burning?"' (24 September, p.245). Amid many heated adjectives you condemn $\mathrm{Dr}$ Sheldrake's $A$ New Science of Life as "the best candidate for burning there has been for many years" because (a) his claim that it can be tested is "preposterous", and (b) the theory is incomplete regarding the "nature and origin" of the morphogenetic fields postulated by Sheldrake and "the means by which they are propagated". The second reason is, you say, "more serious", adding that "hypotheses can be dignified as theories only if all aspects of them can be tested".

This second objection, if it were partial grounds for making a publication a candidate for burning, would prevent the publication of any hypothesis until it had been articulated to its last detail - a sure method of stifling all innovation.

For the first objection, (a) above, three arguments are advanced: (i) the experiments are time consuming; (ii) it would be possible to explain away negative results; (iii) no grantmaking agency would support the

experiments. Argument (i) would condemn all research into inheritance, not just that proposed by Sheldrake; argument (ii) applies in principle to any experiment, but is in this case vacuous since Sheldrake clearly states that he would regard failure as disproof; and argument (iii) is equally empty in its appeal to "higher authority" without any indication as to why no agency would support the experiments.

I share Nature's concern expressed in the comment that the public should not gain the impression that science contains irrational elements. But the way to combat this impression is by displaying rationality.
SIR - In a leading article (Nature 24 September, p.245) you reject Dr Sheldrake's morphogenetic fields as "pseudo science" on the grounds that he does not prescribe their nature or origin, or discuss how their laws of propagation might be discovered. But the properties of heat, light and sound were investigated long before there was any understanding of their true nature, and electricity and magnetism originally had exactly the status that you criticized in the hypothetical water-divining example. Were such investigations pseudoscience?

You claim that hypotheses can be dignified as theories only if all aspects of them can be tested. Such a criterion would bar general relativity, the black hole and many other concepts of modern science from being regarded as legitimate scientific theories.

The discussion of Dr Sheldrake's proposed experiments and their falsifiability is rendered void since it assumes $a$ priori that the experiments will fail.

The rapid advances in molecular biology to which you refer do not mean very much. If one is on a journey, rapid progress on the way implies neither that one is close to one's destination, nor that the destination will be reached at all by continuing to follow the same road.

By referring to "self-respecting grantmaking agencies" you show a concern not for scientific validity but for respectability. The fundamental weakness is a failure to admit even the possibility that genuine physical facts may exist which lie outside the scope of current scientific descriptions. Indeed, a new kind of understanding of nature is now emerging, with concepts like implicate order and subject-dependent reality (and now, perhaps iformative causation). These developments have not yet penetrated to the leading journals. One can only hope that the editors will soon cease to obstruct this avenue of progress, and instead encourage reviews of the field.

University of Cambridge, UK

B.D. JOSEPHSON

\section{Non-random survival}

$\mathrm{S} t \mathrm{R}$ - Barrie Pearson (Nature 3 September,

p.6) states that non-random survival (Flew's revised formulation of the principle of natural selection, Nature 16 July, p.192) is "an empirically empty concept if the range of possibilities the non-random survivors were selected from is unknown".

Fortunately, and contrary to what Pearson appears to believe, the "range of possibilities" is known in quite a number of cases in which the variation amongst juvenile members of an animal population can be shown to be far greater than the variation amongst the adults. This has been demonstrated for populations of snails, lizards, sparrows, fossil cave bears and humans: in some cases the selection is stabilizing and in other cases it is directional. Natural selection would thus seem to have a satisfactory empirical basis.

The depressing thing about the evolutionist/ creationist controversy is not so much the heated arguments about the "status" of the theory of evolution as the fact that the creationists are attempting to sell as scientific a theory which most scientists had abandoned as inadequate long before Darwin's theory was ever thought of: even Cuvier found that one creation was hardly enough! As a theory attempting to explain as much as possible of the way in which the world of living organisms arrived at its present state, without resorting to metaphysical explanations, the neo-Darwinian theory wins hands down over the creationist theory. Thus Pearson's "creatures of reason" are quite right to prefer neo-Darwinism to creationism if they want a theory based - as far as possible - on physical rather than metaphysical grounds. And this, after all, is the essence of the scientific enterprise.

Odense, Denmark

\section{Names for proteins}

SIR - We were glad to see the reference by Brian F.C. Clark (Nature 6 August, p.491) on the prospects for standardizing nomenclature for an index of human and other mammalian cell proteins separated by two-dimensional gel electrophoresis. Lest disproportionate resources be spent on a catalogue of specialized nomenclature, we would urge that parallel projects yielding precise chemical identification (where feasible) are essential.

We believe that it is well within present competence to characterize the perhaps 30,000 protein strucures produced in measurable amount in each species and to tabulate a good deal of accessory information about them. However, the ultimate method for identifying chemical compounds, which is understood by people in diverse fields, is through covalent structure. Proteins are no exception. Determination of only a few residues of an unknown protein can usually serve to identify the group to which it belongs ${ }^{1}$ if the sequence of a closely related structure or homologue in another mammal has already been determined Identity of sequence also serves to clarify the many situations in which proteins of almost identical structure have rather different properties in gels and in which immunological tests are misleading.

It is not generally realized how extensive is the collection of protein sequences already elucidated. We have just completed the integration of data from the Atlas of Protein Sequence and Structure, Vol.5, and its three supplements with the more recent data, including that derived from nucleic acid sequences ${ }^{2}$. There are more than 1,600 entries in the collection. (Within an entry we describe information on structures less than 5 per cent different from one another, such as alleles.)

We have also grouped the data into superfamilies and families: sequences in the same superfamily are significantly similar using statistical tests, whereas sequences in the same family within a superfamily typically are less than 50 per cent different from one another. In the current collection there are almost 500 superfamilies and 750 families; over 140 of these superfamilies and 219 families contain at least one mammalian sequence. There are some 200 entries containing human sequences.

M.O. DAYHOFF, L.T. HUNT,

W.C. BARKER, B.C. ORCUTT,

L.-S. YeH, H.R. CHEN, D.G. GEORGE National Biomedical Research Foundation, Georgetown University Medical Center, Washington DC 20007, USA

1. Dayhoff, M.O. \& Orcutt, B.C. Proc. natn. Acad. Sci U.S.A. 76, 2170-2174 (1979)

2. Protein Sequence Data Tape 81 (National Biomedical Research Foundation, Washington DC, 1981). 